\title{
Experimental Study on Failure Law and Mechanism of Red Sandstone under Ultrasonic Vibration Excitation
}

\author{
Jiyao Wang $\mathbb{D}^{1},{ }^{1}$ Xufeng Wang $\mathbb{D D}^{1}$ Xuyang Chen ${ }^{1}{ }^{1}{ }^{1}$ Liang Chen $\mathbb{D D}^{1,2}$ Zhanbiao Yang $\left(\mathbb{D},{ }^{3,4}\right.$ \\ Zechao Chang $\left(\mathbb{0},{ }^{1}\right.$ Lei Zhang $\left(\mathbb{0},{ }^{1}\right.$ and Zhijun Niu $\mathbb{1}^{1}$ \\ ${ }^{1}$ School of Mines, Jiangsu Engineering Laboratory of Mine Earthquake Monitoring and Prevention, \\ China University of Mining \& Technology, Xuzhou 221116, China \\ ${ }^{2}$ State Key Laboratory of Coal Resources and Safe Mining, China University of Mining and Technology, Xuzhou 221116, China \\ ${ }^{3}$ State Key Laboratory of Coking Coal Resource Development and Comprehensive Utilization, Pingdingshan 467000, China \\ ${ }^{4}$ Research Institute of Coal Mining and Utilization, Pingdingshan Tian'an Coal Industry Co., Ltd., Pingdingshan 467000, China \\ Correspondence should be addressed to Xufeng Wang; wangxufeng@cumt.edu.cn
}

Received 1 December 2021; Revised 11 January 2022; Accepted 26 January 2022; Published 17 February 2022

Academic Editor: Jianyong Han

Copyright (C) 2022 Jiyao Wang et al. This is an open access article distributed under the Creative Commons Attribution License, which permits unrestricted use, distribution, and reproduction in any medium, provided the original work is properly cited.

\begin{abstract}
Rock breakage is inevitable for creating openings in underground engineering operations. Ultrasonic vibration has been attracting extensive attention for such a practice considering its outstanding performance in rock breakage. In order to understand the fundamental failure mechanism of rocks subjected to ultrasonic vibrations, based on P-wave monitoring and the direct current electric method, we captured the evolution of the failure process of the red sandstone. In addition, we fundamentally analyse the failure mechanisms of the red sandstone using numerical simulation and microscopy scans. It was found that extensive fractures were initiated due to the ultrasonic vibration and the fractures propagated downwards forming a conical shape. The apparent resistivity became as high as $320000 \Omega$ being 16 times the initial resistivity. The fracture propagated downwards as deep as $41 \mathrm{~mm}$. The maximum damage parameter on the testing sample could be as high as 0.68 , and it completely failed after $140 \mathrm{~s}$ of ultrasonic vibration duration. As a result of numerical simulation, it was found that the microfractures and pores in the testing sample were activated due to the stress wave resulting from the ultrasonic vibration leading to the fracture propagation and eventually complete failure. Through comparing the performance of uniaxial compressive loading and ultrasonic vibration techniques in rock damage, it was concluded the latter has a much higher capacity and competence in rock breakage.
\end{abstract}

\section{Introduction}

The underground engineering operations have been surging in the past decades in both mining engineering and tunnelling engineering due to the decrease of mineral resources in shallow depth and available space on the surface $[1,2]$. As such, the rock breakage has been significantly important and increasing the rock breakage efficiency as well as decreasing the associated cost has attracted significant attention from researchers [3]. The current common rock breakage methodologies include drilling and blasting, machinery, and hydraulic fracturing as well as thermal breakage [4-7]. It is noteworthy that these methods have common limitations of being high cost and lower rock breakage efficiency and as a result, adversely affect the rock breakage performance in the field.

Rock is a heterogeneous material having extensive micropores and defects [8]. As such, if the rock is under a constant cyclic loading, the internal pores and defects would be activated leading to fracture propagation and eventually failure in the macro scale. To date, the failure mechanism of the rock under cyclic loading conditions has been extensively investigated. Guo et al. [9] has examined the evolution of the failure process of red sandstone under a cyclic loading up to $100 \mathrm{MPa}$ and hence concluded that the hysteresis loop indicates the internal failure and a reduction in the hysteresis 
energy to carry the load. It was found as the hysteresis energy decreases during the cyclic loading testing, the load-carrying capacity of the rock would decrease as well. Taheri et al. [10] carried out the cyclic testing on the sandstone subjected to uniaxial compressive loading as well as triaxial loading condition. It was found that under a high confinement condition, a small number of loading cycles would initiate the rock failure followed by a complete failure after more loading cycles. Yan et al. [11] carried out dynamic cyclic testing on granite subjected to triaxial loading condition using the split-Hopkinson bar (SHPB) and examined the mechanical behaviour and pore size variation as well as the change in the hydraulic conductivity of the granite during the test using nuclear magnetic resonance (NMR). It was found that as the number of cycles increases, the pore size in the sample started to decrease followed by increasing. On the other hand, the rock strength tended to increase followed by decreasing whereas the hydraulic conductivity constantly increased.

Nowadays, ultrasonic vibration has attracted extensive attention from rock mechanics researchers due to its excellent performance in rock breakage. The research mainly falls into a few categories including failure mechanism in the rock resulting from ultrasonic vibration and ultrasonic facilities modification and optimization for rock mechanicsrelated purposes. For instance, the materials of the ultrasonic facilities have been investigated $[12,13]$. The driller of ultrasonic facilities has been studied as well $[14,15]$. These research outcomes provided alternative methodologies for rock breakage. In addition, Neeson and Lucas [16] examined the evolution of the fractures and strength variation of the fully saturated porous rock subjected to ultrasonic vibration. It confirms the feasibility of ultrasonic vibration in reducing rock strength. Yin et al. [17] examined the strength of coal specimens under various static compressive loadings subjected to ultrasonic vibration. They also capture the evolution of the fracture propagation using a CT scan. As a result, it was found that the strength of the coal specimen tended to decrease as the static compressive strength applied to the specimen increased. Tang et al. [18] defined the fracture propagation of the coal specimen in three stages being the micropores formation, fracture propagation leading to form bigger pores, and eventually complete failure of the coal specimen. They successfully implemented their research into coal seam gas drainage practice. Zhao et al. $[19,20]$ visually observed the microfracture propagation of granite after 0,2 , and 4 mins damage by ultrasonic vibration using an electric microscope. It confirmed that the ultrasonic vibration enhanced the propagation of the micropores and defects in the rock, and the tensile failure of the microdefects was the main cause of the rock failure. Yang et al. [21, 22] examined the fracture propagation of the rock specimen under uniaxial compressive loading using the parallel network electrical instrument (WBD) and confirmed such a technique performs well in monitoring the evolution of the fracture propagation of small rock specimens.

As opposed to the aforementioned studies, in this research, we examined the fracture propagation in the red sandstone due to ultrasonic vibration damage followed by further analysing the failure mechanism in the rock breakage. The scope of the paper is in Section 2, where we introduced research methodologies and sample preparation as well as the testing facility; in Section 3, we presented our testing results along with data analysis; in Section 4, we investigated the failure mechanism of the red sandstone subject to ultrasonic vibration damage and in Section 5, we made a remarkable conclusion.

\section{Experimental Design}

2.1. Sample Preparation and Experiment Facility. The rock specimens were red sandstone obtained from the city of Xuzhou, Jiangsu Province. Two types of specimens were cored including the rectangle sample $(50 \times 50 \times 100 \mathrm{~mm})$ and cylindrical samples $(50 \mathrm{~mm}$ in diameter and $100 \mathrm{~mm}$ in length). All the specimens were ground so each end is flat and smooth. In order to ensure the consistency of the specimens, the $\mathrm{P}$-wave of each was monitored to identify the outlier samples having wave velocities less than the average value. The mechanical properties of the red sandstone are summarised in Table 1.

The core facilities in this research are the ultrasonic vibration component (see Figure 1) and direct current electricity monitor (see Figure 2). The former consists of an ultrasonic generator to generate ultrasonic waves, a transducer to transfer electrical energy to mechanical energy, an amplitude transformer to enlarge the vibration amplitude as well as an air compressor to stabilize the pressure. This component has power as high as $1500 \mathrm{w}$, frequency $20 \mathrm{kHz}$, vibration amplitude $40 \mathrm{um}$, voltage up to $220 \mathrm{~V}$, current up to $10 \mathrm{~A}$, and up to $1 \mathrm{MPa}$ loading pressure. The data acquisition was achieved by the WBD system developed by Huizhou Geological Safety Research Institute in Anhui province.

Rock normally fails in a few stages in sequence being elastic deformation, microfracture initiation, macrofracture formation, fracture propagation, and eventually complete failure. Such a failure mechanism is highly associated with the evolution of the internal fractures of the rock. It is noteworthy that the electrical resistivity would increase with the evolution of the fractures in the rock. The distribution of the electrical resistivity in the rock could be mapped out by the direct current electrical method, and thereafter, the apparent electrical resistivity in the rock can be visually illustrated with the aid of software such as Tecplot.

As the $\mathrm{P}$-wave velocity is sensitive to the microstructural variation, such a technique was adopted to detect the change in the micropores in the rock (see Figure 3). During the test, the P-wave velocities at various stages were captured and hence correlated with the micropore size in the rock.

\subsection{Electrical Detection Method and Electrode Arrangement.} Electrical resistivity is a key geophysical parameter for rocks. It can be obtained by the direct current electrical method and hence used to indicate the internal failure or fractures in the rock. The principle is through supplying the current to the electrodes, the electrical resistivity can be determined by the 
TABle 1: Physical and mechanical parameters of red sandstone.

\begin{tabular}{lccccc}
\hline Elastic modulus $(\mathrm{GPa})$ & Poisson ratio & $\begin{array}{c}\text { Compressive } \\
\text { strength }(\mathrm{MPa})\end{array}$ & Extension strength $(\mathrm{MPa})$ & Internal friction angle $\left(^{\circ}\right)$ & Cohesion $(\mathrm{MPa})$ \\
\hline 60 & 0.25 & 54.2 & 6.12 & 42.44 \\
\hline
\end{tabular}

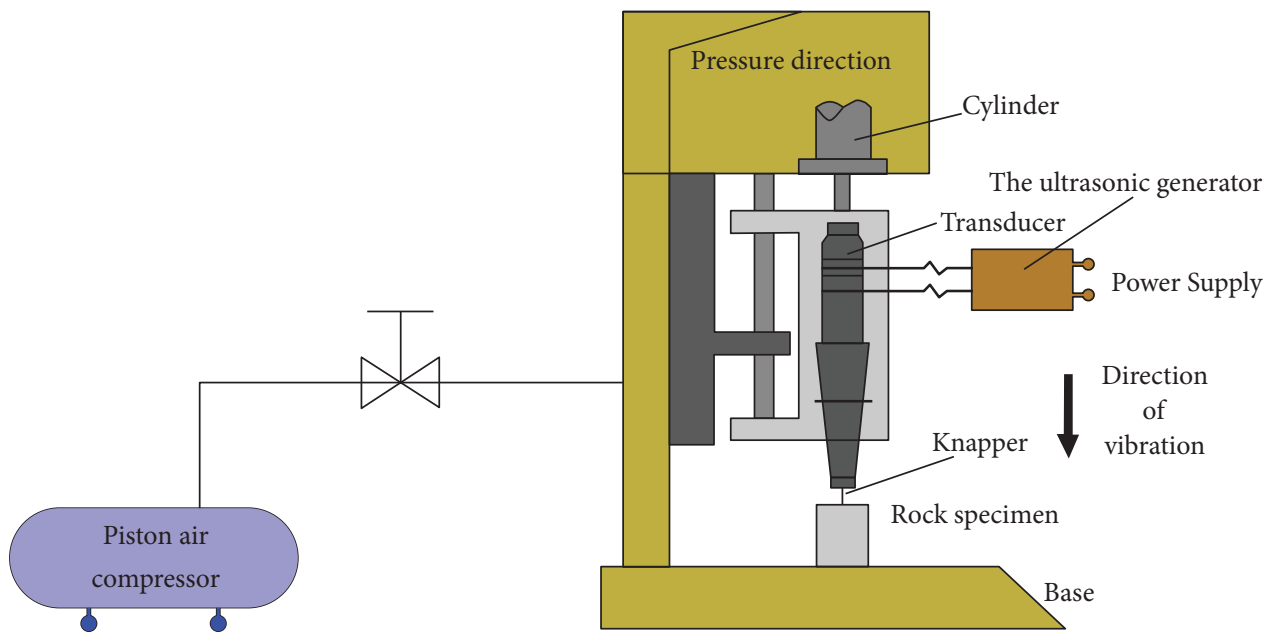

FIgURE 1: Schematic of ultrasonic vibration inducer.

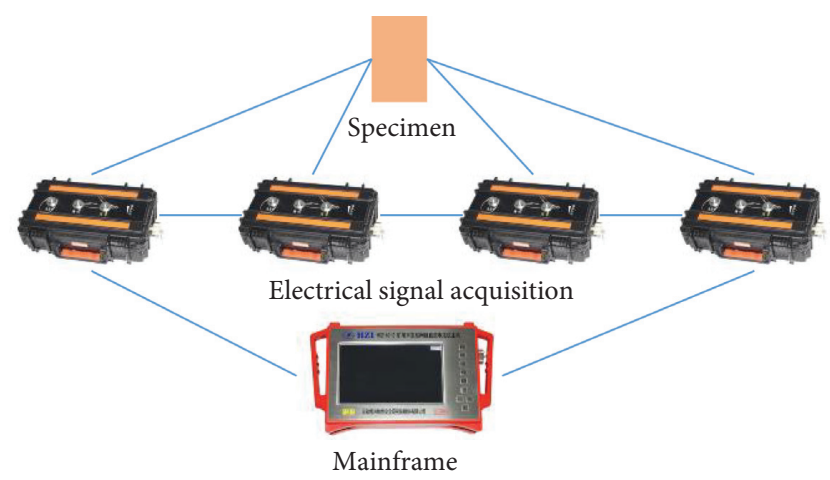

Figure 2: Direct current electrical monitor.

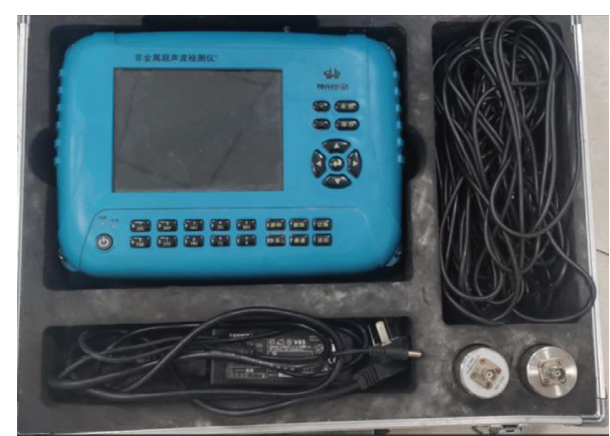

Figure 3: Nonmetal ultrasonic monitoring device.

voltage drop between the electrodes. The resistivity distribution provides an estimation of the fracture distribution as the electrical resistivity can be correlated with fractures in the rock. Nakamura and Kusumi [23] carried out extensive tests to determine the electrical resistivity of various rock specimens with different porosities and hence confirmed the electrical resistivity would increase with the size of the pores in the rock. Coli et al. [24] successfully captured the fractures in the excavation surface in underground operations based on their research in the correlation between the rock pore size and hydraulic conductivity as well as electrical resistivity. Niu et al. [25] further analysed the effect of the fracture propagation on the electrical resistivity of the rock based on the direct current electrical method and confirmed that the electrical resistivity would spike when the macro fractures were formed.

The conventional electrodes were installed by drilling the holes on the sample. However, the red sandstone specimen was too small, and it was believed that the drilled holes would affect its performance. As such, the electrode stickers were attached onto the specimen surface. The glue was able to tolerate high temperatures and conduct electricity. The sticker was made of copper and had a dimension of $0.5 \times 0.8 \mathrm{~mm}$ and a thickness of $0.05 \mathrm{~mm}$.

For a rectangular sample, eight electrodes were attached onto each of the four sides and connected to the electrical mainframe through wires (see Figure 4). This arrangement was able to capture the real-time electrical resistivity distribution during the test.

2.3. Experiment Procedures. The ultrasonic vibrations were generated for six different periods of time being $40 \mathrm{~s}, 60 \mathrm{~s}$, $80 \mathrm{~s}, 100 \mathrm{~s}, 120 \mathrm{~s}$, and $140 \mathrm{~s}$, respectively (see Table 2). The electrical resistivity at different locations of the specimen was monitored straight after each vibration. Ten measurement points with $1 \mathrm{~cm}$ in between were arranged at each side of the specimen (see Figure 5). After each test, the P-wave velocities at three cross-sections of the rock specimen including the upper monitoring plane, middle monitoring plane, and lower monitoring plane were recorded. 


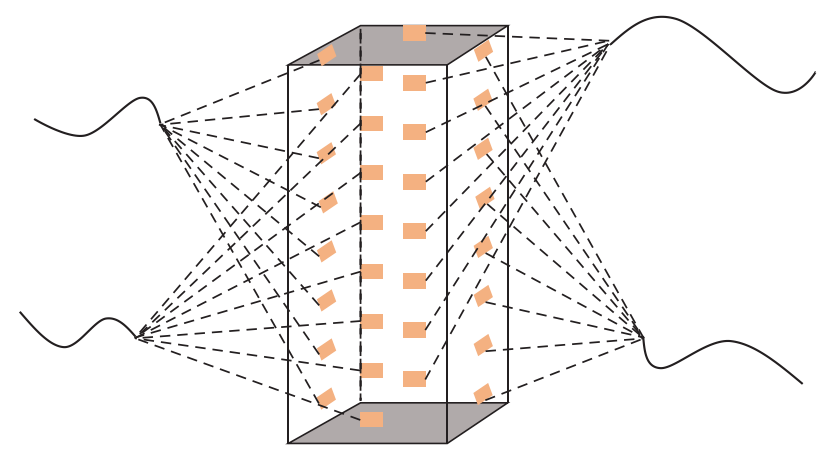

(a)

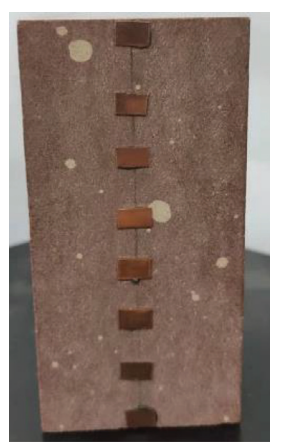

(b)

Figure 4: Distribution of electrodes. (a) Electrode distribution diagram (b) Physical picture of electrode distribution.

TABLE 2: Ultrasonic vibration generation experimental program.

\begin{tabular}{lcc}
\hline Specimen number & $\begin{array}{c}\text { Top load static } \\
\text { pressure }(\mathrm{MPa})\end{array}$ & Excitation time (s) \\
\hline 1 & 0.02 & 40 \\
2 & 0.02 & 60 \\
3 & 0.02 & 80 \\
4 & 0.02 & 100 \\
5 & 0.02 & 120 \\
6 & 0.02 & 140 \\
\hline
\end{tabular}

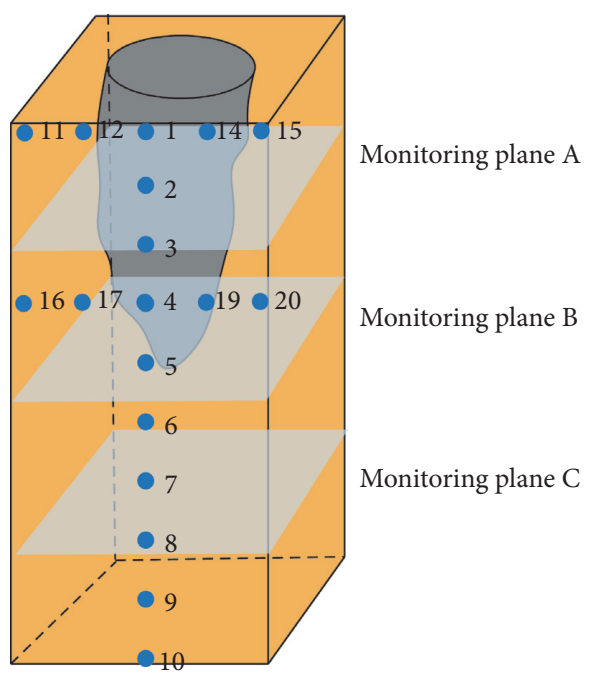

FIgURE 5: Measurement points distribution for the rectangular specimen.

\section{Experimental Results and Data Analysis}

3.1. Ultrasonic Vibration Effect on Rock Compressive Strength. The fractures in the cylindrical specimen propagated during the ultrasonic vibration leading to the complete failure of the rock (see Figure 6). Figure 6(a) shows the severe crack at the top section of the rock specimen whereas Figure 6(b) shows the bulky crush after the test. Both can be seen as failures. After each ultrasonic vibration, the cylindrical samples were tested under uniaxial compressive loading to determine their uniaxial compressive strength (UCS). The influence of each ultrasonic vibration on the UCS of the rock specimen is illustrated in Figure 7.

As seen from Figure 7, the damage in the rock due to the ultrasonic vibration became visually clear after the vibration has been being generated for $40 \mathrm{~s}$. As the ultrasonic vibration being generated longer, the area of the damage on the surface of the rock specimen increased and so did the length and the width of the fractures in the rock. As a result, the UCS of the rock specimen decreased as evidenced by Figure 7 where the UCS decreased from 54.2 $\mathrm{MPa}$ to $40 \mathrm{MPa}$ equivalent to approximately $26 \%$ reduction.

3.2. Fracture Propagation Induced by Ultrasonic Vibration. In addition to the tests on cylindrical samples, more tests have been carried out on rectangular samples to capture the fracture propagation induced by ultrasonic vibration. The testing conditions for rectangular samples were exactly the same as those for cylindrical samples. As a result, it was found that the damage area on the top of the sample as well as the fracture length at the side of the sample increased as the ultrasonic vibration was generated for a longer period of time (see Figures 8 and 9).

Overall, the damage diameter on the top of the sample increased from $19 \mathrm{~mm}$ when ultrasonic vibrating for $40 \mathrm{~s}$ to $38 \mathrm{~mm}$ when ultrasonic vibrating for $140 \mathrm{~s}$. It is noteworthy that the increase rate in the damage diameter was more significant from $19 \mathrm{~mm}$ at $40 \mathrm{~s}$ vibration duration to $35 \mathrm{~mm}$ at $100 \mathrm{~s}$ vibration duration. By contrast, the increase rate became slower thereafter leading to an increase from $35 \mathrm{~mm}$ to $38 \mathrm{~mm}$. The damage depth increased from $2 \mathrm{~mm}$ at $40 \mathrm{~s}$ vibration duration to $28 \mathrm{~mm}$ at $140 \mathrm{~s}$ vibration duration. The fracture length at the sample side increased from $5 \mathrm{~mm}$ at $40 \mathrm{~s}$ vibration duration to $10 \mathrm{~mm}$ at $80 \mathrm{~s}$ vibration duration at a slower rate followed by a spike increase to $41 \mathrm{~mm}$ at $140 \mathrm{~s}$ vibration duration.

It has been observed that the rock failure induced by ultrasonic vibration is a progressive failure starting with the initial crack at the area of the rock closer to the vibration generator. Thereafter, the fractures at the top surface of the specimen formed followed by propagating downwards. Over the course of fracture propagation, the bulk at the top section of the sample fell off along with crushed fine materials until the complete failure of the rock specimen (see Figure 10). As 


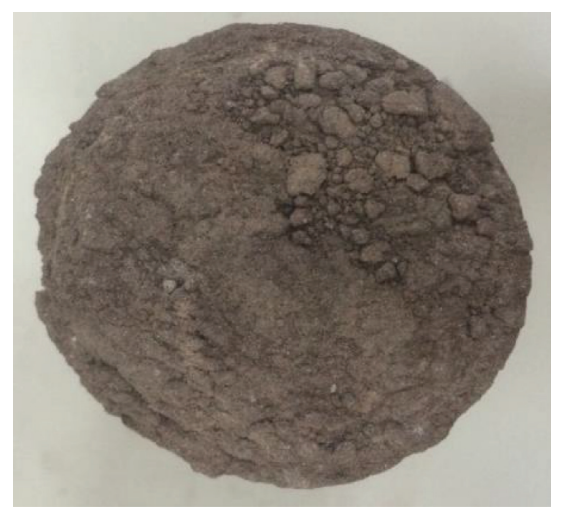

(a)

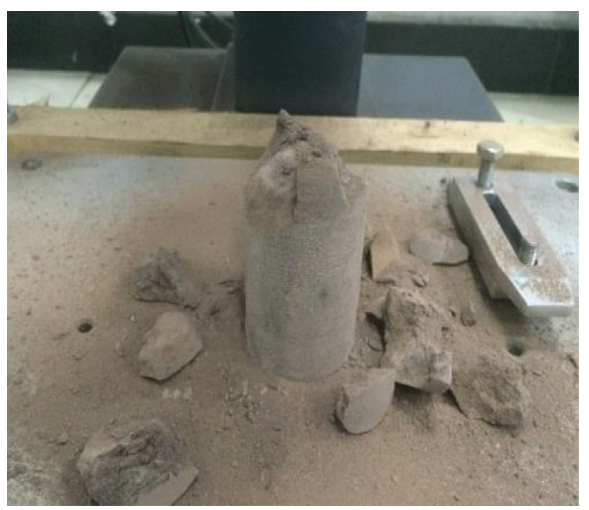

(b)

FIGURE 6: Failure observation of rock specimen after ultrasonic vibration. (a) Upper crushing of specimen (b) Large fragments separated from the body of the specimen.

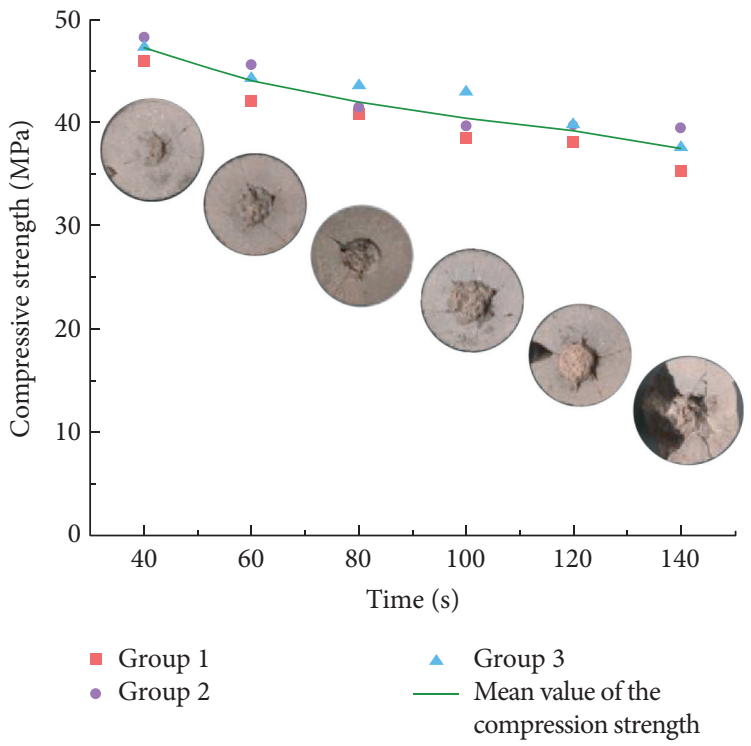

FIGURE 7: Effect of ultrasonic vibration on the UCS of the rock specimen.

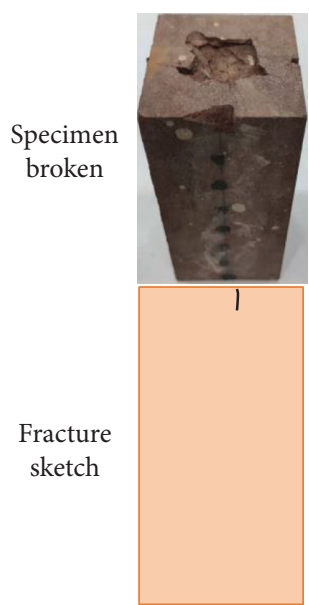

(a) $40 \mathrm{~s}$

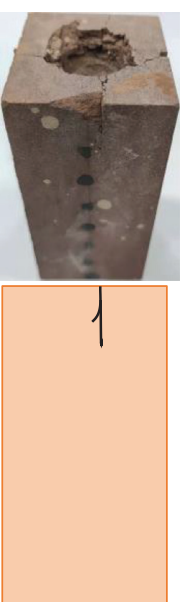

(b) $60 \mathrm{~s}$

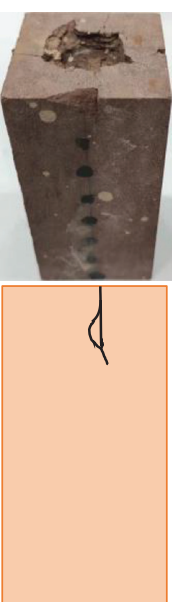

(c) $80 \mathrm{~s}$

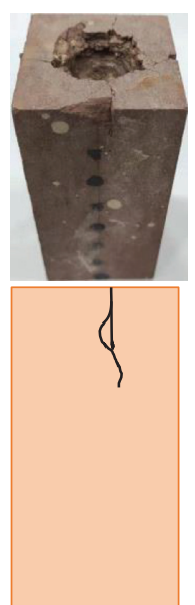

(d) $100 \mathrm{~s}$

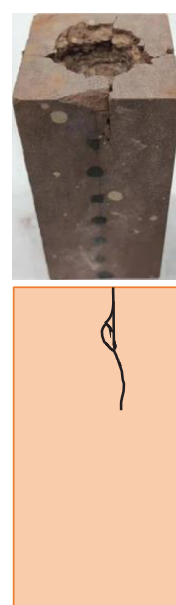

(e) $120 \mathrm{~s}$

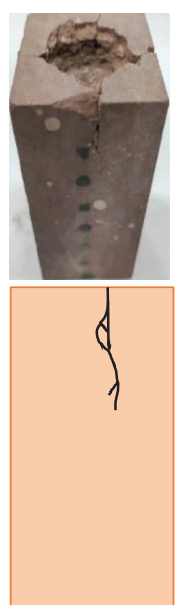

(f) $140 \mathrm{~s}$

Figure 8: Illustration of fracture propagation. (a) $40 \mathrm{ss}$ (b) $60 \mathrm{ss}$ (c) $80 \mathrm{~s}$. (d) $100 \mathrm{~s}$. (e) $120 \mathrm{~s}$. (f) $140 \mathrm{~s}$. 


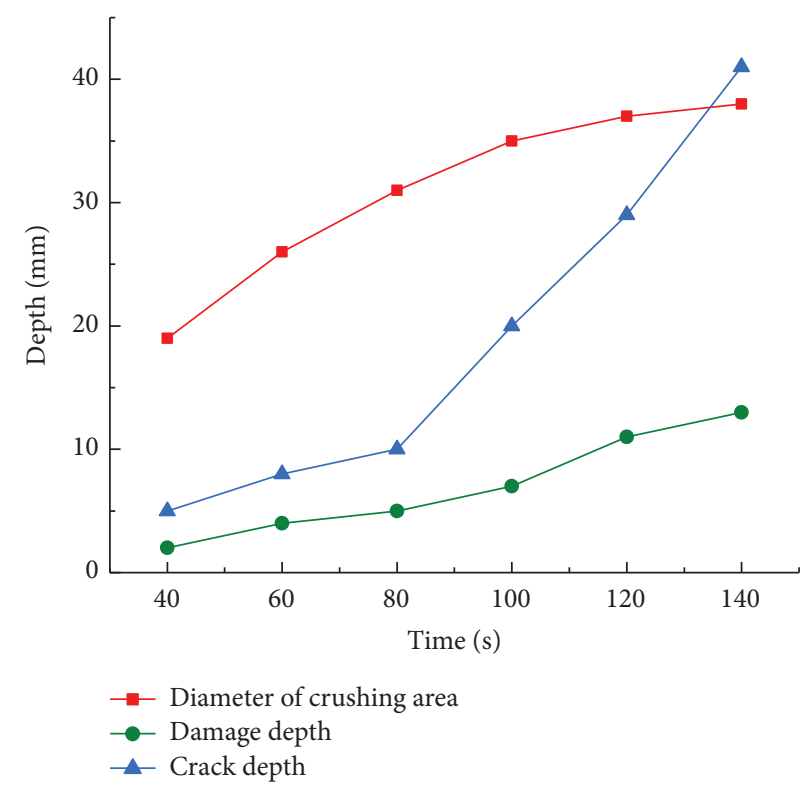

Figure 9: The change of different failure parameters with time.

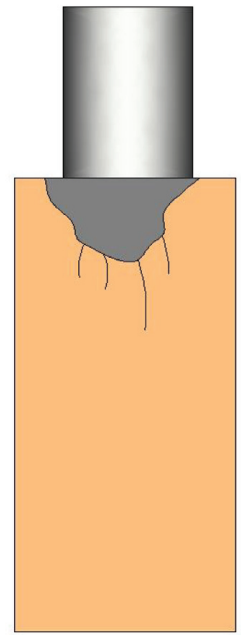

(a)

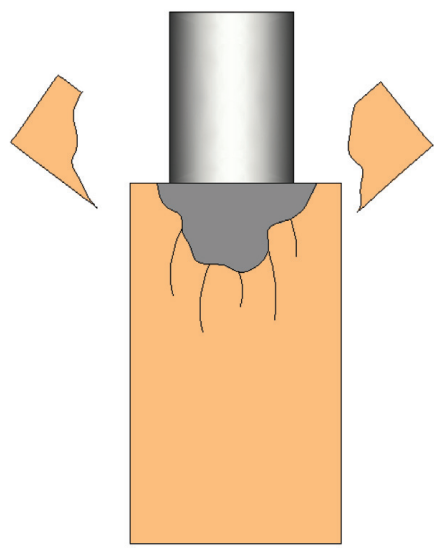

(b)

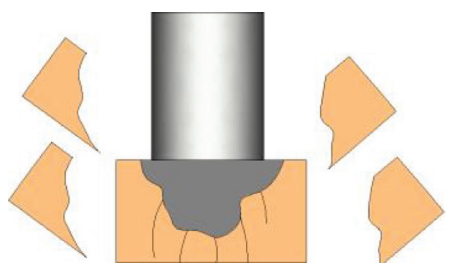

(c)

FIGURE 10: Illustration of progressive failure in rock during the test. (a) Broken starting. (b) In the broken. (c) Completely broken.

opposed to conventional uniaxial compressive tests and triaxial tests, ultrasonic vibration could lead to a rock failure to a higher extent.

\subsection{Electrical Resistivity Distribution in Rectangular Specimen} during the Test. The direct current electrical method was used to capture the electrical resistivity at different locations of the rock samples at different time durations subjected to ultrasonic vibration. The electrical resistivity distribution in the rock sample after different ultrasonic vibration durations is illustrated in Figure 11. At the $40 \mathrm{~s}$ vibration duration, the top surface of the rock sample exhibited an electrical resistivity as high as $80000 \Omega$ whereas the other portions of the sample showed a lower resistivity. As the ultrasonic vibration being generated longer, the electrical resistivity at the top surface of the rock sample increased and it decreased gradually as moving downwards. When the sample was under the longest ultrasonic vibration for $140 \mathrm{~s}$, the electrical resistivity at the top surface of the rock specimen was up to $320000 \Omega$ being equivalent to 16 times of that before inducing the ultrasonic vibration.

It is noteworthy that the fractures due to the ultrasonic vibration tend to concentrate more as opposed to that due to the conventional testing. In order to investigate the fracture propagation induced by the ultrasonic vibration, the electrical resistivity distribution along the longitudinal direction was mapped out based on the measurements at points 1 and 2 at the top, points 4 and 5 in the middle, and points 8 and 9 at the bottom (see Figure 12). In addition, the electrical resistivity along the lateral direction was mapped out based on the measurements at points $11,12,1,14$, and 15 at the top 


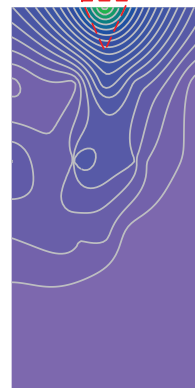

(a) $40 \mathrm{~s}$

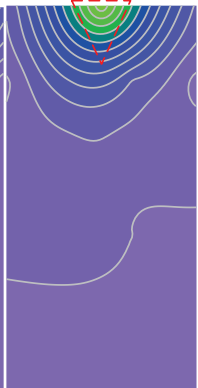

(b) $60 \mathrm{~s}$

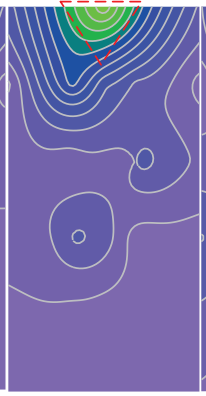

(c) $80 \mathrm{~s}$

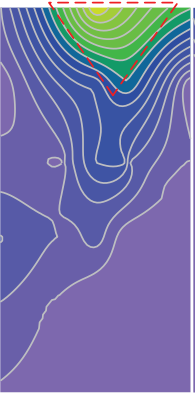

(d) $100 \mathrm{~s}$

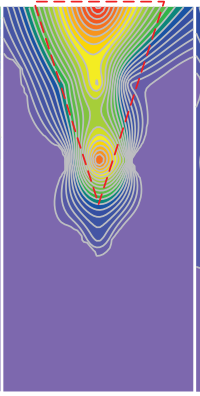

(e) $120 \mathrm{~s}$

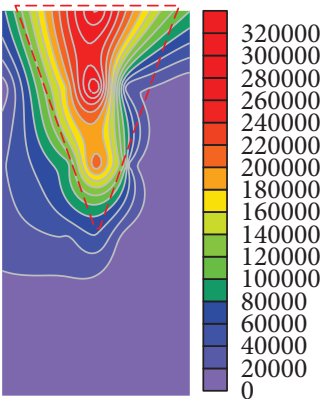

(f) $140 \mathrm{~s}$

FIGURE 11: Electrical resistivity distribution in the rock specimen at various ultrasonic vibration durations. (a) 40 s. (b) $60 \mathrm{~s}$. (c) $80 \mathrm{~s}$. (d) $100 \mathrm{~s}$. (e) $120 \mathrm{~s}$. (f) $140 \mathrm{~s}$.

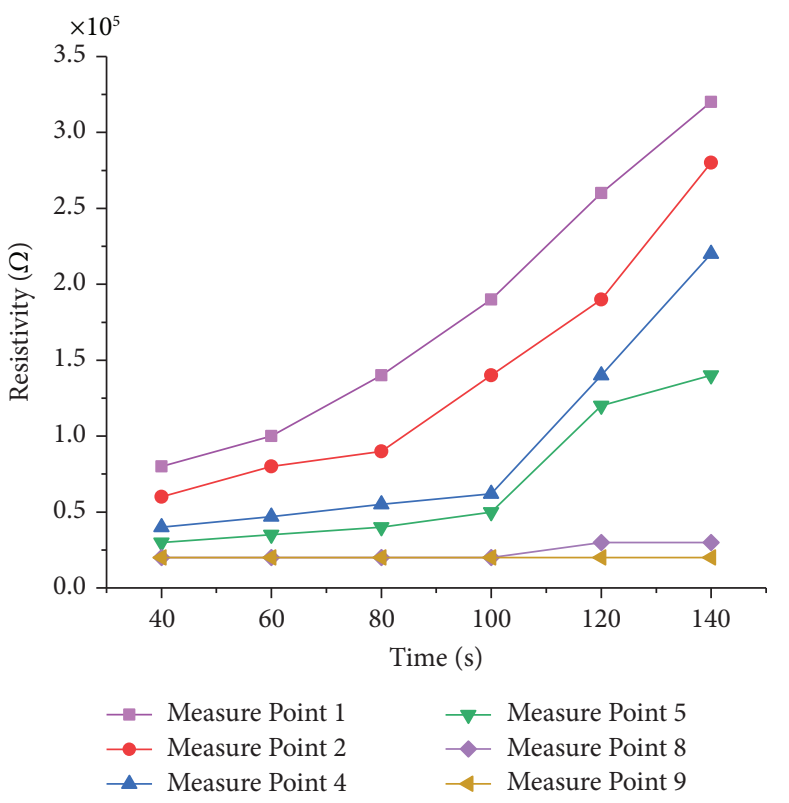

FIGURE 12: Electrical resistivity distributions along the longitudinal direction.

section as well as points $16,17,4,19$, and 20 in the middle (see Figure 13).

As Figure 12 shows, the electrical resistivity at points 1 and 2 increased as the ultrasonic vibration was generated longer indicating the damage at the top section of the rock became more extensive. By contrast, the electrical resistivity at points 4 and 5 remained constantly if ultrasonic vibration was generated for less than $100 \mathrm{~s}$ indicating that the energy generated by the ultrasonic vibration would be absorbed by the top section of the rock specimen first. Thereafter, the electrical resistivity increased from $5000 \Omega$ to $12500 \Omega$ indicating the top section has failed and the middle section started absorbing energy induced by ultrasonic vibration.

As the fractures propagated only down to the middle section of the rock specimen as demonstrated by Figure 11, we decided to analyse the electrical resistivity distribution along the lateral direction based on the measurements at points $11,12,1,14$, and 15 at the top (see Figure 13(a)) as well as 16, 17, 4, 19, and 20 in the middle (see Figure 13(b)). It could be seen the centre part of the rock specimen has the highest electrical resistivity whereas as moving towards the sides, the electrical resistivity gradually decreased. The peak value of the electrical resistivity could be up to $320000 \Omega$ at the top and $230000 \Omega$ in the middle of the rock specimen. This indicated that the majority of fractures occurred in the centre of the specimen highlighting the good control of the ultrasonic vibration direction and excellent energy concentration generated by the vibration. Such an advantage would no doubt enhance the rock breakage.

3.4. P-Wave Velocities Analysis Results. In order to identify the damage at different locations of the rock specimen due to the ultrasonic vibration, three cross-sections at the top, middle, and bottom of the specimen were selected for measuring the $\mathrm{P}$-wave velocities. Table 3 shows the $\mathrm{P}$-wave velocities at different locations after ultrasonic vibration for various periods of time.

P-wave velocity is sensitive to any minor variation of microstructures in the rock such that it could be used to reflect the fracture distribution in the rock according to

$$
D_{m}=1-\left(\frac{V_{p i}}{V_{p 0}}\right)^{2} \text {, }
$$

where $D_{m}$ is the damage parameter as a result of ultrasonic vibration, $V_{p i}$ is the $\mathrm{P}$-wave velocity after $i$ th ultrasonic vibration in $\mathrm{m} / \mathrm{s}$, and $V_{p 0}$ is the $\mathrm{P}$-wave velocity before the ultrasonic vibration in $\mathrm{m} / \mathrm{s}$. The $\mathrm{P}$-wave velocities and damage parameters at different locations of the rock specimen after various vibration durations are shown in Figure 14.

It could be seen that the damage became visually apparent at cross-section A after ultrasonic vibration for $40 \mathrm{~s}$. As the duration of ultrasonic vibration increased from $40 \mathrm{~s}$ to $140 \mathrm{~s}$, the P-wave velocity decreased from $4625 \mathrm{~m} / \mathrm{s}$ to $2741 \mathrm{~m} / \mathrm{s}$. In the meantime, the damage parameter increased from 0.09 to 0.68 . In addition, as per cross-section $\mathrm{B}$, the $\mathrm{P}$-wave velocity decreased at a low rate from $4799 \mathrm{~m} / \mathrm{s}$ after $40 \mathrm{~s}$ vibration to $4625 \mathrm{~m} / \mathrm{s}$ after $60 \mathrm{~s}$ vibration whereas the damage parameter increased from 0.02 to 0.08 . Thereafter, the P-wave velocity further decreased to $3546 \mathrm{~m} / \mathrm{s}$ after $140 \mathrm{~s}$ vibration at a higher rate whereas the damage parameter increased to 0.46 . By contrast, the P-wave velocity remained stable at the cross-section $\mathrm{C}$ regarding the duration of the 


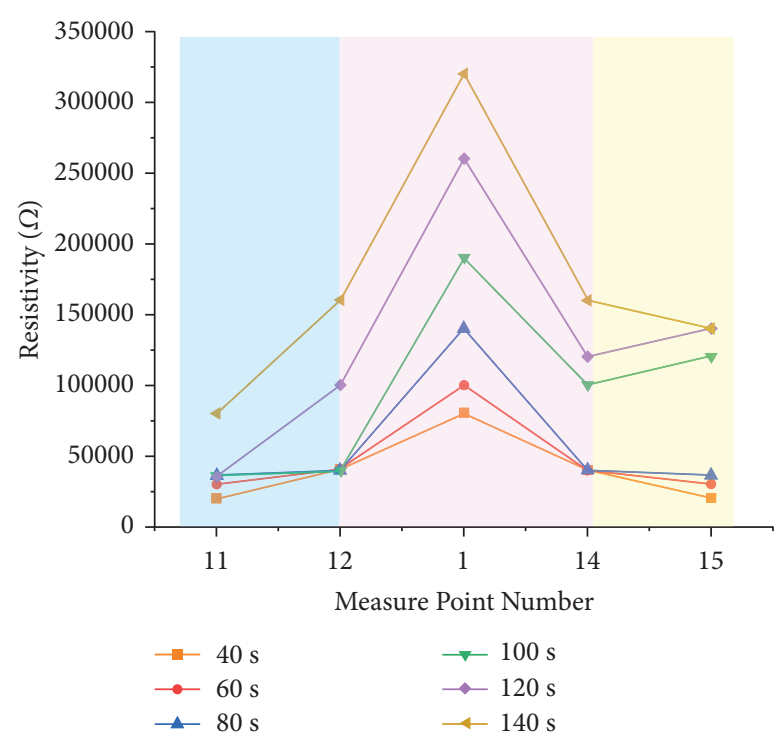

(a)

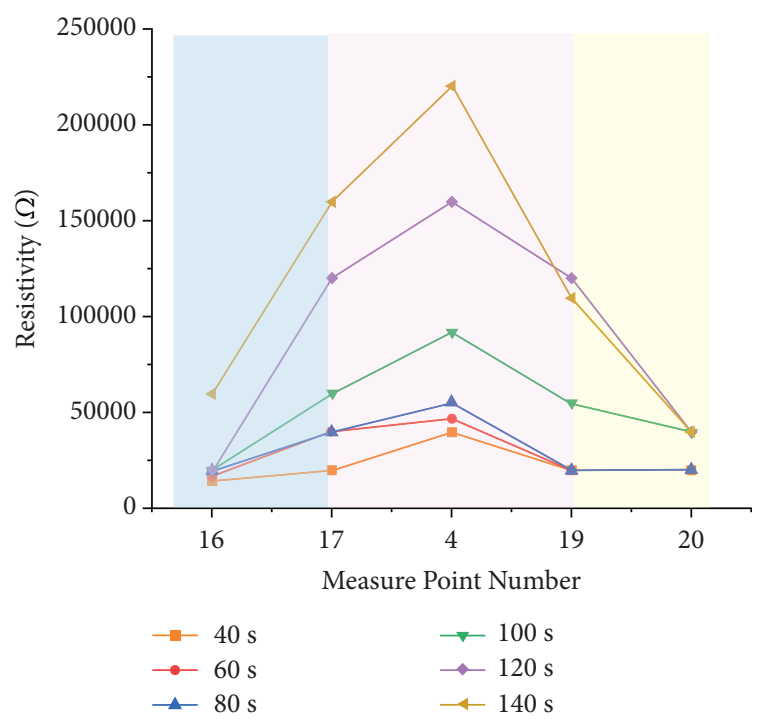

(b)

FIGURE 13: Electrical resistivity distributions along the lateral direction. (a) At the top section of the rock specimen. (b) In the middle of the rock specimen.

TABle 3: P-wave velocities after ultrasonic vibration for various periods of time.

\begin{tabular}{lcccccc}
\hline Monitoring location & Initial wave velocity & $40 \mathrm{~s}$ & $60 \mathrm{~s}$ & $80 \mathrm{~s}$ & $100 \mathrm{~s}$ & $120 \mathrm{~s}$ \\
\hline Section A & 4875 & 4323 & 4121 & 3521 & 3156 & 2810 \\
Section B & 4863 & 4791 & 4653 & 4355 & 4020 & 3766 \\
Section C & 4871 & 4869 & 4866 & 4860 & 4842 & 4836 \\
Average & 4889 & 4968 & 4998 & 4756 & 4531 & 4378 \\
\hline
\end{tabular}

ultrasonic vibration. This could be attributed to the intact rock at cross-section $\mathrm{C}$ where the fractures did not propagate to.

All the observations and testing results reinforced that the ultrasonic vibration technique can be well controlled in terms of the vibration direction and rock damage area. It has distinguished advantages over other rock breakage techniques by having more energy concentration on the damage area in the rock and better direction orientation.

\section{Discussion}

Due to the current study of ultrasonic vibration excitation, broken rock is still in its infancy, so this article from the perspective of the abovementioned test results of ultrasonic vibration excitation, the failure mechanism of the rock are discussed for the failure mechanism in the process of rock specimen broken for further exploration, with the method of numerical simulation to simulate the process of specimen damage analysis.

A numerical simulation was conducted using PFC 2D to further analyse the failure mechanism associated with rock breakage induced by the ultrasonic vibration. The size of the model is consistent with the cylindrical rock specimen tested, $50 \mathrm{~mm}$ in diameter and $100 \mathrm{~mm}$ in length (see Figure 15). The ultrasonic vibration was simulated by the wall module following the sine form:

$$
\mu=A \sin (2 \pi f t)
$$

where $A$ is the vibration amplitude being 40 um in this study and $f$ is the vibration frequency being 2000 in this study.

In order to ensure the accuracy of the numerical simulation test, the microscopic parameters should be calibrated properly first. After selecting the relevant microscopic parameters, the numerical simulation was carried out to obtain the values of each parameter, and the corresponding macro mechanical parameters obtained from laboratory tests were compared and analysed. Through continuous debugging, until the simulated calculation value is close to the real value obtained in the room, a set of reasonable microscopic parameters are finally selected as shown in Table 4.

Figure 16 shows that the uniaxial compressive strength measured in the complete sample chamber is $67.8 \mathrm{MPa}$, while the uniaxial compressive strength calculated by numerical simulation is $68.4 \mathrm{MPa}$, which is less than $1 \%$. Since there is no compaction stage in numerical simulation, the strain generated by numerical simulation is higher than that of the laboratory test. The elastic modulus is the secant modulus of the stress-strain curve. The elastic modulus obtained by numerical simulation is $3.44 \mathrm{GPa}$, and the elastic modulus obtained by experiment is $3.42 \mathrm{GPa}$, with only 0.6 difference between them. Therefore, the selection of model parameters is reasonable. 

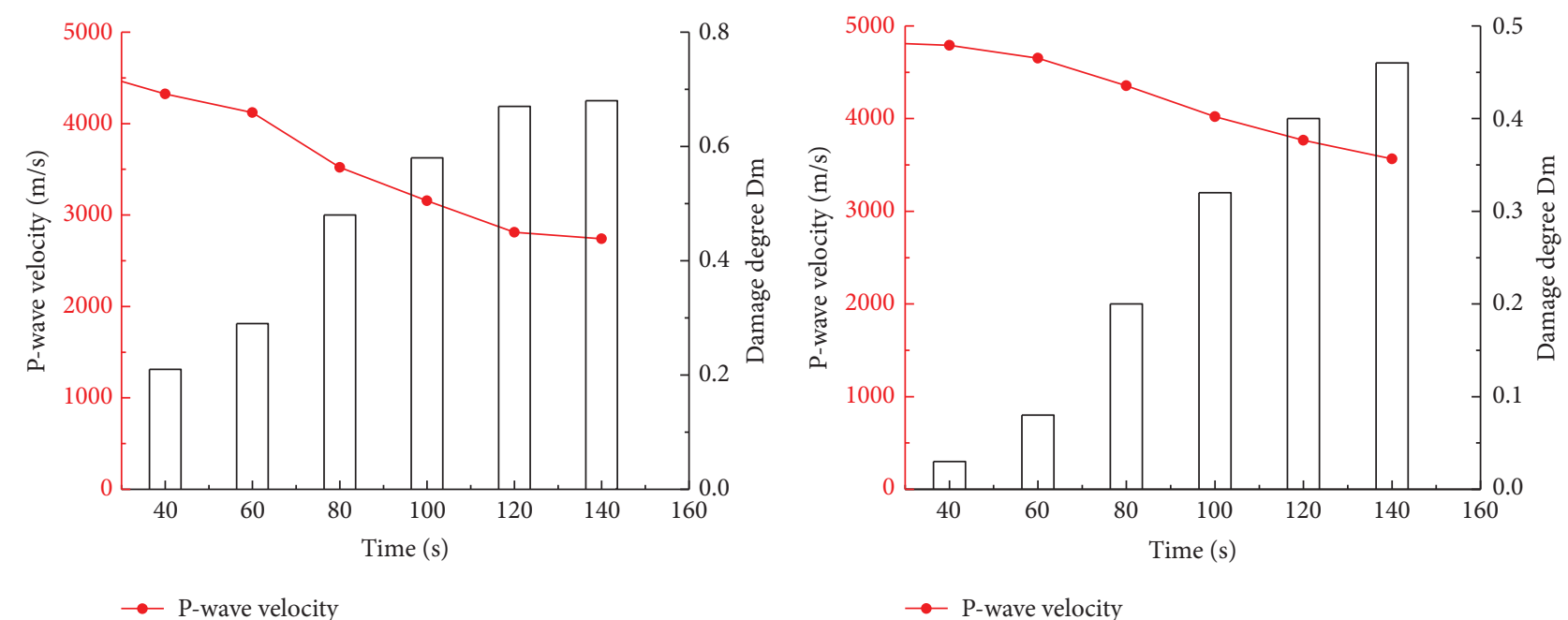

(a)

(b)

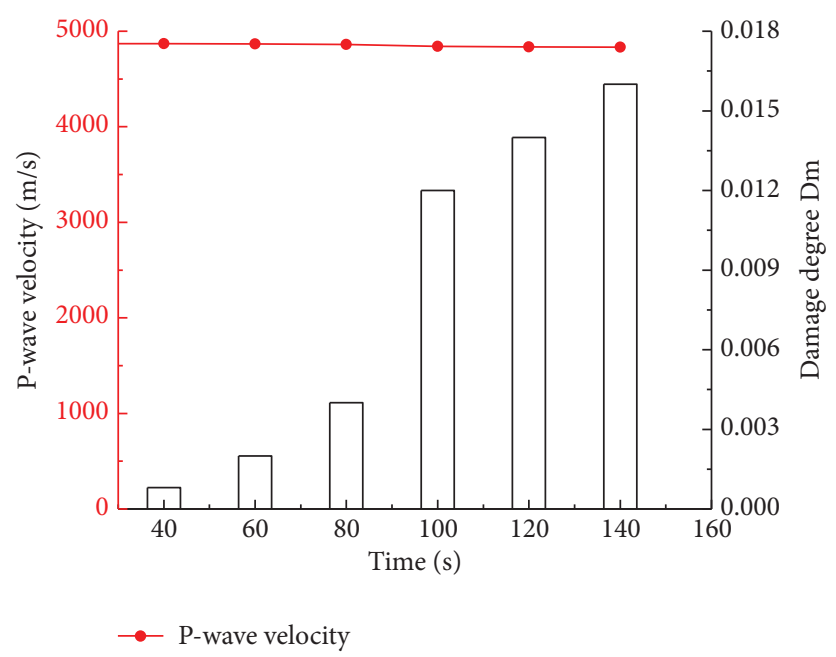

(c)

Figure 14: P-wave velocities and damage parameters at different locations of the rock specimen after various ultrasonic vibration durations. (a) Section A. (b) Section B. (c) Section C.

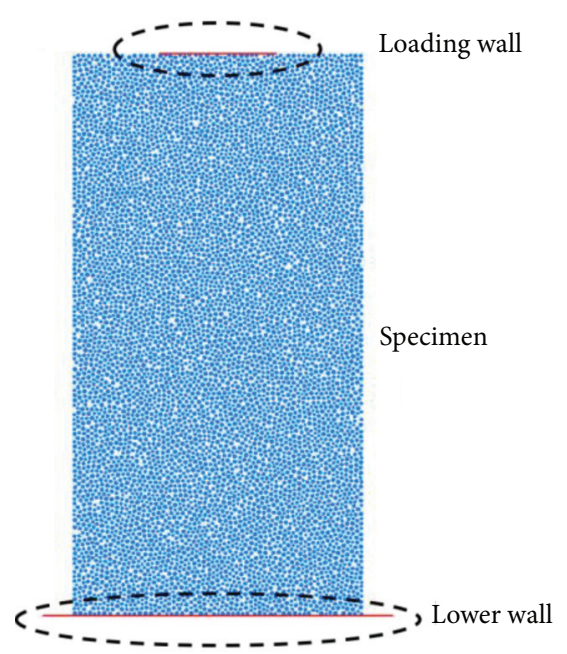

Figure 15: Schematic illustration of the numerical model. 
TABLE 4: Microscopic parameter values.

\begin{tabular}{lc}
\hline Microscopic parameter & Microscopic parameter values \\
\hline Minimum particle radius $(\mathrm{mm})$ & 0.15 \\
Maximum particle radius $(\mathrm{mm})$ & 0.3 \\
Density $\left(\mathrm{kg} / \mathrm{m}^{3}\right)$ & 2700 \\
Particle normal/tangential stiffness ratio & 1 \\
Particle friction coefficient & 0.45 \\
Parallel bond modulus $(\mathrm{GPa})$ & 1.7 \\
Normal strength of parallel bond $(\mathrm{MPa})$ & 31 \\
Tangential strength of parallel bond $(\mathrm{MPa})$ & 39 \\
\hline
\end{tabular}

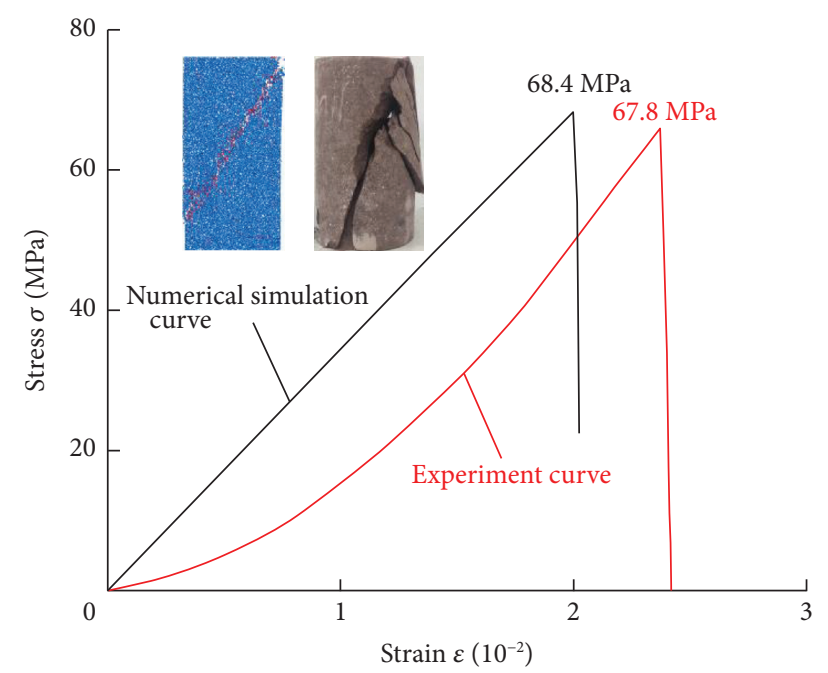

FIGURE 16: Comparison between numerical simulation and experimental stress-strain curves.

The fracture propagation at various ultrasonic vibration durations was simulated (see Figure 17). The cracks due to shear and tension were highlighted in blue and red in Figure 17 which shows the fracture propagation at five different points of time $(a, b, c, d$, and $e)$. Figure 17(a) shows the initiation of the fracture starting from the left side followed by moving towards the right as illustrated in Figure 17(b). The cracks were mainly associated with tension at these two stages. Figure $17(\mathrm{c})$ shows the fracture propagation in the conical shape where the failure at the top is mainly associated with shear crack whereas that at the bottom is a combination of shear and tension. These three stages $(a, b$, and $c)$ reflect the progressive failures as illustrated in Figure 8 . Thereafter, the fractures further propagated downwards and towards the rock surface (see Figure 17(d)) until the complete failure had bulks falling off (see Figure 17(e)).

In order to further verify the development law of cracks in the process of ultrasonic vibration excitation in numerical simulation, the red sandstone samples were scanned by using an electron microscope before ultrasonic vibration excitation. At the end of the ultrasonic vibration excitation test, rock samples were extracted from the fracture area and fracture development area of the specimen for the SEM test. SEM results before ultrasonic vibration excitation are shown in Figure 18, while SEM results after ultrasonic vibration excitation are shown in Figure 19.
As shown in Figure 18, red sandstone have evenly distributed grains and very few internal micro defects. The grain surface is smooth and surrounded by cement. The only defects are the pores and minor cracks at the interface between grains and cement. After the test with $140 \mathrm{~s}$ ultrasonic vibration duration, the failure interface is smooth indicating a shear failure. In a conventional rock breakage by static loading condition, as the loading rate is slow, the fracture would initiate from the internal defects in the rock and propagate through an optimum pathway with the least resistance. By contrast, the high vibration velocity and frequency of the ultrasonic generator could result in an extremely fast stress wave propagation through the rock sample, even faster than the crack propagation from the internal defects. As such, the rock fails in shear only before the massive crack propagating from internal defect as demonstrated in Figure 19(a). On the other hand, the crack interface exhibits cracks in grain and step-wise pattern (see Figure 19(b)). Cracks in grain are mainly associated with tensile failure whereas the step crack is associated with shear failure. Such an observation is consistent with the numerical simulation which shows a combination of the shear and tensile failures induced by ultrasonic vibration after the test. In addition, extensive crushed materials were observed after the test indicating a shear failure at the failure interface. 


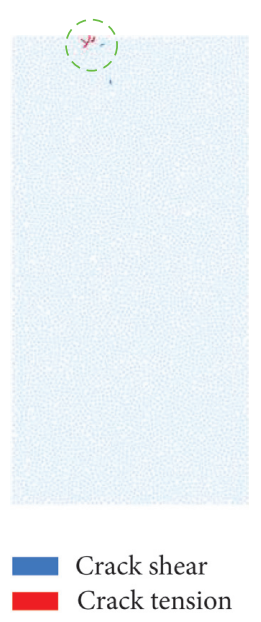

(a)

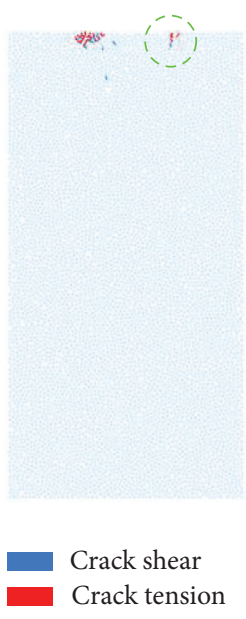

(b)

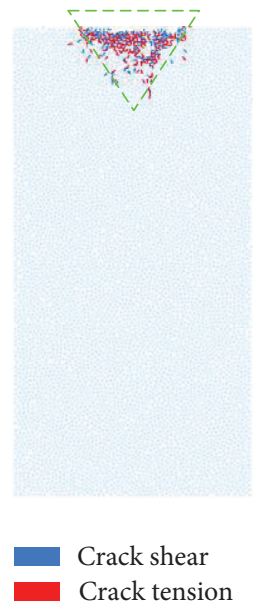

(c)

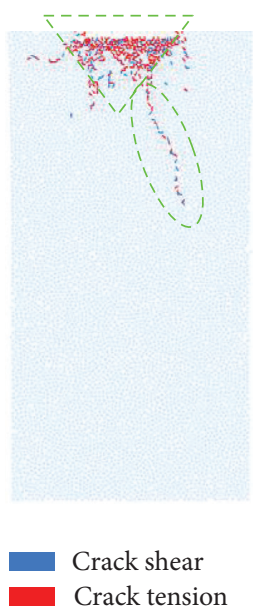

(d)

Figure 17: Progressive fracture propagation simulated in PFC 2D. (a) Typical time A. (b) Typical time B. (c) Typical time C. (d) Typical time D.

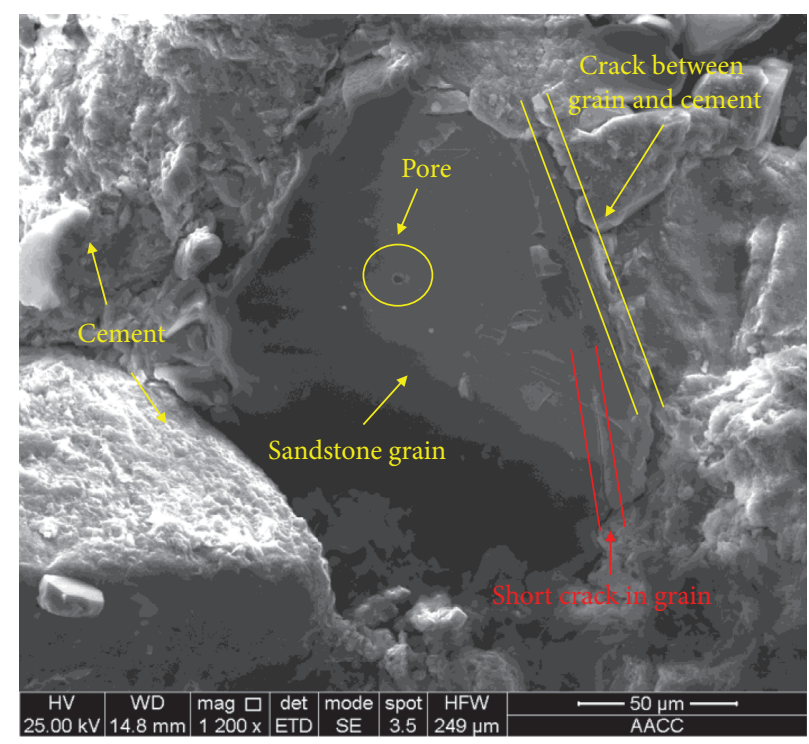

FIGURE 18: Electrical microscopy scan before the test.

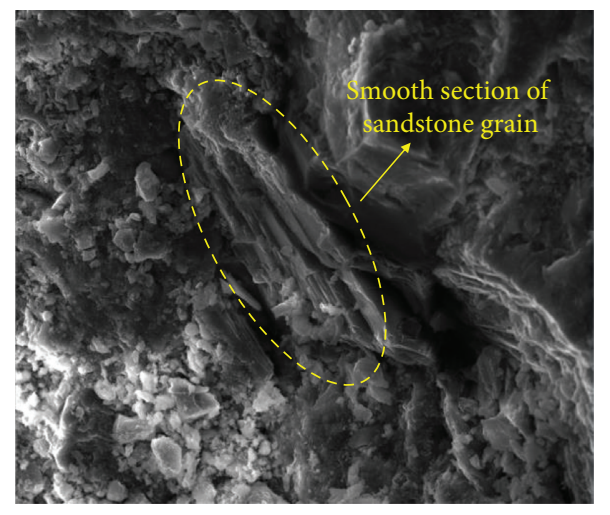

(a)

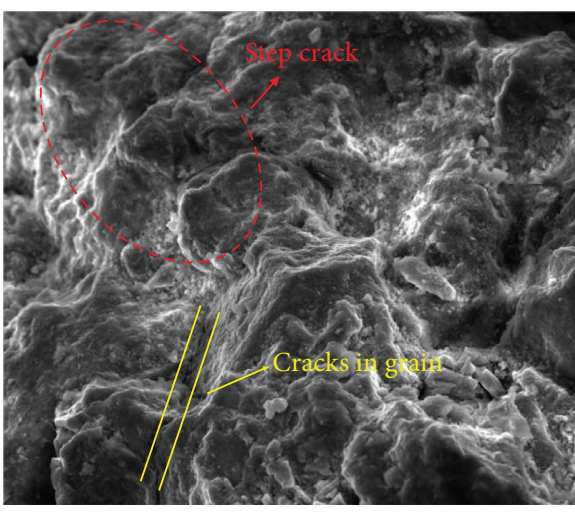

(b)

Figure 19: Electrical microscopy scan of the sample after $140 \mathrm{~s}$ ultrasonic vibration duration. (a) Fracture place. (b) Crack zone. 


\section{Conclusions}

The failure mechanisms associated with ultrasonic vibrationinduced damage on rock have been comprehensively investigated using laboratory testing and numerical simulation methodologies. The distinguished advantages of the ultrasonic vibration technique over the conventional rock breakage methodology and the uniaxial compressive loading, in particular, were also highlighted. We hence made the following remarkable conclusions:

(1) As a result of an ultrasonic vibration for up to $140 \mathrm{~s}$, the UCS of red sandstone decreased by $26 \%$. The fracture was as long as $41 \mathrm{~mm}$ whereas the depth of the damage was around $28 \mathrm{~mm}$.

(2) As a result of direct current electrical monitoring on the red sandstone specimen, the electrical resistivity increased from $8000 \Omega$ before the test to $320000 \Omega$ at the failure. In addition, the observation showed that the energy generated by ultrasonic vibration is mainly concentrated at the centre of the rock specimen.

(3) As a result of P-wave velocities monitoring, the damage parameter could be as high as 0.68 demonstrating its excellent capability for rock breakage.

(4) As a result of electrical microscopy scan and numerical simulation of the damage on the rock induced by ultrasonic vibration, it is confirmed that the rock failure is associated with a combination of tensile and shear resulting from the compressive stress waves frequently generated by the ultrasonic vibration generator.

\section{Data Availability}

The data used to support the findings of this study are available from the corresponding author upon request.

\section{Conflicts of Interest}

The authors declare that there are no conflicts of interest regarding the publication of this paper.

\section{Acknowledgments}

This research was supported by the National Natural Science Foundation of China (no. 51874282), Six Talent Peaks Project in Jiangsu Province (no. GDZB-052), Postgraduate Research \& Practice Innovation Program of Jiangsu Province (KYCX21_2363), and State Key Laboratory of Coking Coal Resource Development and Comprehensive Utilization of China Pingmei Shenma Group Open Project (no. 41040220181107). The authors are grateful for these supports.

\section{References}

[1] D. Li, Y. Li, M. Asadizadeh, H. Masoumi, P. C. Hagan, and S. Saydam, "Assessing the mechanical performance of different cable bolts based on design of experiments techniques and analysis of variance," International Journal of Rock Mechanics and Mining Sciences, vol. 130, Article ID 104307, 2020.

[2] D. Li, Y. Li, and W. Zhu, "Analytical modelling of loaddisplacement performance of cable bolts incorporating cracking propagation," Rock Mechanics and Rock Engineering, vol. 53, no. 8, pp. 3471-3483, 2020.

[3] L. Zhang, X. Wang, J. Wang, and Z. Yang, "Mechanical characteristics and pore evolution of red sandstone under ultrasonic high-frequency vibration excitation," AIP $A d$ vances, vol. 11, 2021.

[4] X. Wang, X. Wang, J. Wang, and Z. Tian, "Feasibility study and prospects of rock fragmentation using ultrasonic vibration excitation," Applied Sciences-Basel, vol. 10, 2020.

[5] Z. Zhang, D. Hou, Z. Guo, Z. He, and Q. Zhang, "Experimental study of surface constraint effect on rock fragmentation by blasting," International Journal of Rock Mechanics and Mining Sciences, vol. 128, 2020.

[6] L. Zhuang, K. Y. Kim, M. Diaz, and S. Yeom, "Evaluation of water saturation effect on mechanical properties and hydraulic fracturing behavior of granite," International Journal of Rock Mechanics and Mining Sciences, vol. 130, 2020.

[7] G. Lu, J. Zhou, Y. Li, X. Zhang, and W. Gao, "The influence of minerals on the mechanism of microwave-induced fracturing of rocks," Journal of Applied Geophysics, vol. 180, Article ID 104123, 2020.

[8] D. Li, M. Cai, and H. Masoumi, "A constitutive model for modified cable bolts exhibiting cone shaped failure mode," International Journal of Rock Mechanics and Mining Sciences, vol. 145, Article ID 104855, 2021.

[9] H. Guo, M. Ji, Y. Zhang, and M. Zhang, "Study of mechanical property of rock under uniaxial cyclic loading and unloading," Advances in Civil Engineering, vol. 2018, Article ID 1670180, 6 pages, 2018.

[10] A. Taheri, A. Royle, Z. Yang, and Y. Zhao, "Study on variations of peak strength of a sandstone during cyclic loading," Geomechanics and Geophysics for Geo-Energy and Geo-Resources, vol. 2, no. 1, pp. 1-10, 2016.

[11] L. Yan, W. Yi, L. Liu, J. Liu, and S. Zhang, "Blasting-induced permeability enhancement of ore deposits associated with low-permeability weakly weathered granites based on the Split Hopkinson pressure bar," Geofluids, vol. 2018, Article ID 4267878, 14 pages, 2018.

[12] K. Noma, Y. Takeda, T. Aoyama, Y. Kakinuma, and S. Hamada, "High-precision and high-efficiency micromachining of chemically strengthened glass using ultrasonic vibration," Procedia CIRP, vol. 14, pp. 389-394, 2014.

[13] E. Bertsche, K. Ehmann, and K. Malukhin, "Ultrasonic slot machining of a silicon carbide matrix composite," International Journal of Advanced Manufacturing Technology, vol. 66, no. 5-8, pp. 1119-1134, 2013.

[14] W. Liu, X. Zhu, and B. Li, "The rock breaking mechanism analysis of rotary percussive cutting by single PDC cutter," Arab Journal of Geoscience, vol. 11, 2018.

[15] E. Pavlovskaia, D. C. Hendry, and M. Wiercigroch, "Modelling of high frequency vibro-impact drilling," International Journal of Mechanical Sciences, vol. 91, pp. 110-119, 2015.

[16] E. Neeson and M. Lucas, "The effects of ultrasonics in fragmentation of saturated porous rock samples," in Proceedings of the 2012 IEEE International Ultrasonics Symposium (IUS), pp. 1982-1985, Dresden, Germany, October 2012.

[17] S. Yin, D. Zhao, and G. Zhai, "Investigation into the characteristics of rock damage caused by ultrasonic vibration," International Journal of Rock Mechanics and Mining Sciences, vol. 84, pp. 159-164, 2016. 
[18] Z. Tang, C. Zhai, Q. Zou, and L. Qin, "Changes to coal pores and fracture development by ultrasonic wave excitation using nuclear magnetic resonance," Fuel, vol. 186, pp. 571-578, 2016.

[19] D. Zhao, S. Zhang, and M. Wang, "Microcrack growth properties of granite under ultrasonic high-frequency excitation," Advances in Civil Engineering, vol. 2019, Article ID 3069029, 13 pages, 2019.

[20] D. Zhao, S. Zhang, Y. Zhao, and M. Wang, "Experimental study on damage characteristics of granite under ultrasonic vibration load based on infrared thermography," Environmental Earth Sciences, vol. 78, 2019.

[21] C. Yang, S. Liu, and H. Yang, "Self-potential response characteristics of red sandstone samples under uniaxial compression," Journal of Geophysics and Engineering, vol. 16, no. 4, pp. 742-752, 2019.

[22] C. Yang, S. Liu, J. Liu, H. Yang, and J. Xie, "Characteristics of self-potential of coal samples under uniaxial compression," Journal of Applied Geophysics, vol. 168, pp. 1-11, 2019.

[23] M. Nakamura and H. Kusumi, "An estimation method of insitu rock masses by characteristic of electric resistivity for jointed rock mass model," Journal of the Society of Materials Science, Japan, vol. 55, no. 5, pp. 458-463, 2006.

[24] N. Coli, G. Pranzini, A. Alfi, and V. Boerio, "Evaluation of rock-mass permeability tensor and prediction of tunnel inflows by means of geostructural surveys and finite element seepage analysis," Engineering Geology, vol. 101, no. 3-4, pp. 174-184, 2008.

[25] Y. Niu, Z. Li, B. Kong et al., "Similar simulation study on the characteristics of the electric potential response to coal mining," Journal of Geophysics and Engineering, vol. 15, no. 1, pp. $42-50,2018$. 